\title{
Leading Higher Institutional Transformation: Empowering Community Educational Engagement (CEE) Through Internet of Things (IoT)
}

\author{
N.H. Shabdin ${ }^{1,2}$ A. Abu ${ }^{1,2, ~ *}$ R.S. Mohamad ${ }^{1,2}$ A. Selamat ${ }^{2}$ M.S. Abdullah ${ }^{1,2}$ N.H.M. \\ Sulaiman $^{1}$ N.F.M. Hashim ${ }^{1}$ M.F.M Alwi ${ }^{1}$ N.A.M. Ezanee ${ }^{1}$ M.K. Shabdin ${ }^{1,2}$ \\ ${ }^{1}$ Kolej Siswa Jaya, Universiti Teknologi Malaysia (UTM KL), Jalan Rejang 4, Taman Setapak Jaya, 54100 Kuala \\ Lumpur \\ ${ }^{2}$ Malaysia-Japan International Institute of Technology (MJIIT), Universiti Teknologi Malaysia (UTM KL), Jalan Sultan \\ Yahya Petra, 54100 Kuala Lumpur \\ ${ }^{*}$ Corresponding author. Email: aminudin.kl@utm.my
}

\begin{abstract}
A new phase of the Industrial Revolution (IR) 4.0 that focuses heavily on interconnectivity, automation, machine learning, and real-time data will ultimately take over the entire supply chain. However, it is not just about investing in new technology and tools to improve institutional system but also focus must be in revolutionizing the way institutional-community operates and grows. This paper aim to share exploratorium module initiated in Community Educational Engagement (CEE) program which coordinated in MalaysiaJapan International Institute of Technology (MJIIT), Universiti Teknologi Malaysia (UTM). The objectives of initiating this program are to accelerate knowledge society with Internet of Things (IoT) which implies the need for a full understanding of important of IoT knowledge, access to information technology and the capability to transfer information into practical knowledge. Success in empowering institutional-community is believed to eventually open a right path in tackling IR 4.0 challenges.
\end{abstract}

Keywords: Community Educational Engagement (CEE), Institutional Transformation, Internet of Things (IoT), Industrial Revolution (IR) 4.0

\section{INTRODUCTION}

The Ministry has carried out initiatives and programmes in line with the Malaysia Education Blueprint 2015-2025 to ensure that higher institutions develop future-proof talents that would meet the demands of industry. This includes a flexible and organic curriculum that the Ministry has implemented as a step in ensuring that our students can access information wherever they are and whenever they want, without being too restricted to the classroom environment as before. The education system in Malaysia undoubtedly developed and transformed in line with the demands of the current market. There is, however, a conflict between the technology and society as a whole at some stage. The pattern of rising ' $\mathrm{e}$ ' such as e-library, elearning, e-health care, e-participation, e-civil society, etc. is appealing to adopt. But would each organisation be converted into an e-organization, contributing to the transition from a community to a information society (ksociety)? However, we see that many have this assumption that ' $\mathrm{e}$ ' accumulation will reflect ' $\mathrm{k}$ ' which points this transformation in the wrong direction.

\subsection{Internet of Things (IoT)}

The Internet of Things is an emerging technological, social, and economic subject. Consumer products, household goods, cars and trucks, manufacturing and service equipment, sensors, and other everyday items combine with Internet connectivity and powerful data analytics technologies that attempt to improve the way we work, live, and play. The Internet of Things incorporates a wide set of ideas from different perspectives that are complex and intertwined. Key concepts which serve as a basis for exploring IoT's opportunities and challenges include:

(a) IoT Definitions: which typically refers to the network connectivity and computing power to devices that allows these devises to create, share and consume data without need to depend on human skills.

(b) Enabling Technologies: there has been the idea of integrating computers, sensors, and networks to track and manage devices since many years back. 
However, increase in public users recently shows that IoT has become closer to public reality.

(c) Connectivity Models: IoT used various models of technological communication which highlighted simple and easy to interact between devices that increased its value among users

(d) Transformational Potential: If transformation towards IoT become reality, people will have change in thinking that is changing them from physical contact to passive engagement through IoT platform. That is how we can see now in current Covid19 pandemic situation, where people stay connected around the world through the use of this IoT technology.

\section{BACKGROUND}

\subsection{Motivation}

As we previously addressed the value of moving knowledge society in the right direction, it was considered that higher institutions still lack leadership capacity through Internet of Things (IoT) discovery. Communities, especially high school students and parents do not know the availability of high-tech instrumentation in universities. Moreover, most kids and parents may still have traditional dream jobs that may no longer be important in the new IR 4.0 market today. This missing link is what MJIIT was trying to achieve with communities to really bridge awareness and learning experience in the CEE programme. Through a well-designed exploratory module, high school students and parents as well as teachers can have a clear picture of the current capacity of MJIIIT to provide Japanese-oriented engineering education. MJIIT offers unique learning facilities through collaboration with Japanese industries that include the Sangaku Renkei Laboratory. The facilities include 72 research laboratories that are specialised in research areas centred on iKohza.

\subsection{Objectives}

This paper highlighted two objectives. First, to explore advantages of Community Educational Engagement (CEE) program handled by higher institutional. Second, to develop new conceptual framework which focus on Internet of Things to be embedded in the CEE program.

\section{COMMUNITY EDUCATIONAL ENGAGEMENT (CEE) PROGRAM}

One of the most established university engagement programs with the community is lifelong learning education to the public [4]. Two aspects of the educational experience that differentiate education from other service experiences as including exclusivity of access; the role of the customer in the process and the longitudinal nature of the educational experience [5]. Universities were in fact the pioneers in expertise that influenced the direction of progress in society. This is particularly important in engineering and technology where there is a significant impact in the knowledge economy [6]. Commitment to community education is one that combines learning goals with community service in ways that can boost both student growth and the common good. In the words of the National Service Learning Clearinghouse America (NSLC), it is "a teaching and learning strategy that integrates meaningful community service with instruction and reflection to enrich the learning experience, teach civic responsibility, and strengthen communities." In addition, to quote Vanderbilt University's Janet S. Eyler (winner of the 2003 Thomas Ehrlich Faculty Award for Service Learning) and Dwight E. Giles, it is; "a form of experiential education where learning occurs through a cycle of action and reflection as students, seek to achieve real objectives for the community and deeper understanding and skills for themselves. In the process, students link personal and social development with academic and cognitive development. experience enhances understanding; understanding leads to more effective action." Community engagement is typically incorporated into a course or series of courses through a project that has objectives for both learning and community action. This project is designed through collaboration between faculty and community partners, such as government agencies or non-governmental organisations. This provides learners with experiential opportunities to learn in real-world environments and develop community engagement skills, while creating resources for community members to address critical needs. CEE programmes are well known to be implemented by many organisations, but it is the first CEE to share Japanese-oriented engineering education through Internet of Things (IoT) exploration in Malaysia educational institution. Participants have opportunities to perform practical learning in the field of robotics and drones, as well as Japanese language.

\section{MJIIT EXPLORATORIUM MODULE FRAMEWORK}

By referring to this concept, one new 'out of box' MJIITcommunity platform was designed in CEE program which combining element of Japan oriented education and Internet of Things (IoT) advance instrument learning. This platform was created because MJIIT was alarmed by public's lacks understanding of science and technology. This platform will be enabled students to learn and explore hi-tech technology possess by MJIIT thus gain their confidence in their ability to understand science phenomena around them. By making IoT science visible, touchable, and accessible to community especially students, MJIIT believe this will influence and improve 
IoT science education in Malaysia. Figure 1 below shows new conceptual framework designed in this CEE program.

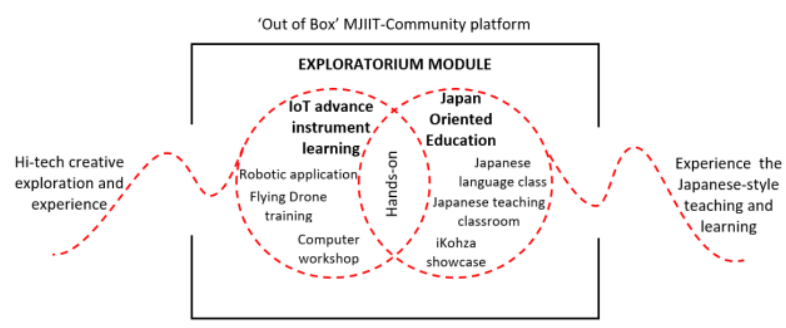

Figure 1 New conceptual framework designed in MJIIT CEE program

Combining these two strong value-added of MJIIT, the new CEE program has gone beyond traditional learning. In this sense, students will gain more interactive and real IoT experience which enhances understanding where understanding leads to more creative and innovative thinking.
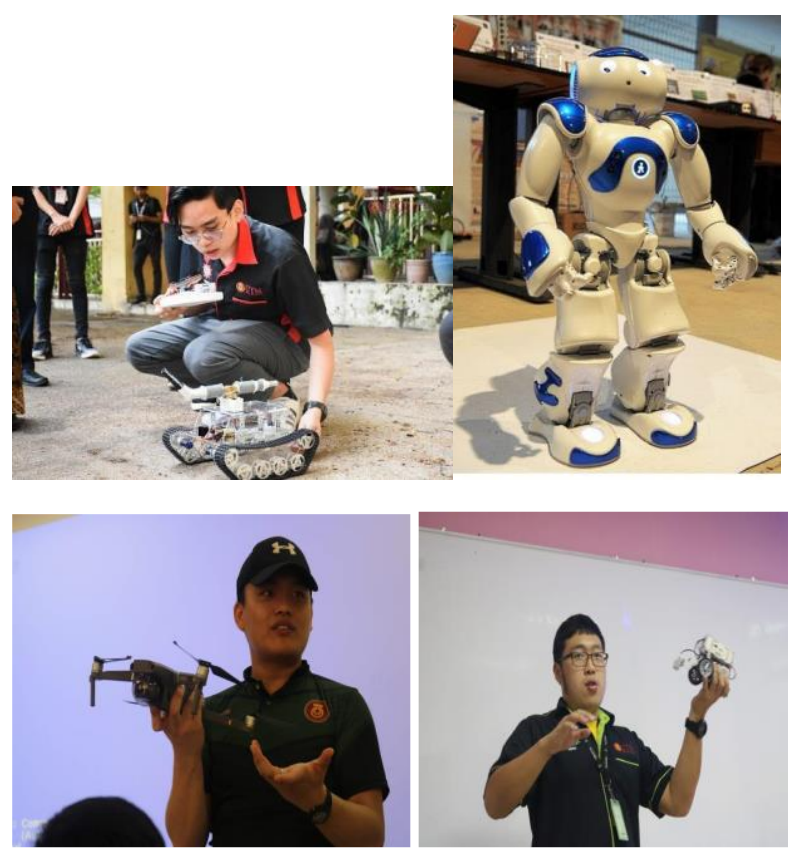

Figure 2 Sharing IOT experience and knowledge by MJIIT students

\section{CEE MJIIT UTM - IMTIAZ MELAKA}

The first batch for this program involved students from Sekolah Menengah Imtiaz Ulul Albab, Melaka. The collaboration was made with Ministry of Entrepreneur Development (MED) and Muafakat IMTIAZ Melaka in obtaining financial support for this program. Kolej Siswa Jaya, UTM Kuala Lumpur also provides accommodations for students participating in this program. MJIIT students and lecturer's involvement also creating more effective and enjoyable campus environment for participants. A total of 135 Imtiaz Malacca students from Form 1 to 5 and 60 students from the diploma and degree programs were involved. Some of the activities that were done by the Imtiaz students throughout the duration of the program were going to various lectures such as AutoCAD class, Japanese Language class, Drone and Robotics class, and basic PC maintenance class. On the weekend of the program, the students sat for an exam that was done to gauge their academic performance in the 3 core subjects Mathematics, Science, and English. UTM students became mentors to the participants which through the results of the test, they correct any errors made during the test and tutor them in topics where they are weak. In fact, this program has benefitted participants with valuable knowledge and skills that they can use beyond the program itself.

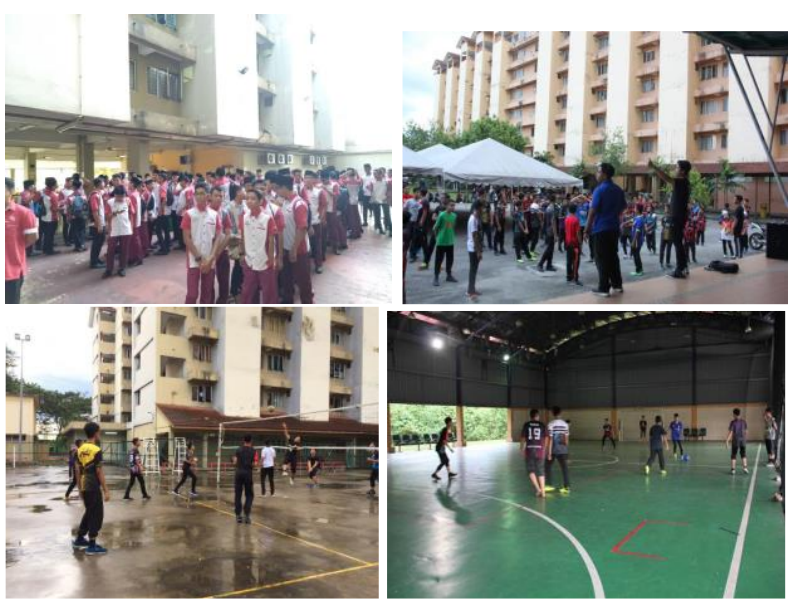

Figure 3 Students from Imtiaz Melaka were accommodated by Kolej Siswa Jaya UTM KL


Figure 4 Participants experience using facilities in MJIIT 
The closing ceremony of the CEE @ MJIIT UTMIMTIAZ was officiated by YB Datuk Seri Mohd Redzuan bin Md Yusof, Minister of Entrepreneur Development, at the Azman Hashim Hall, Universiti Teknologi Malaysia Kuala Lumpur.

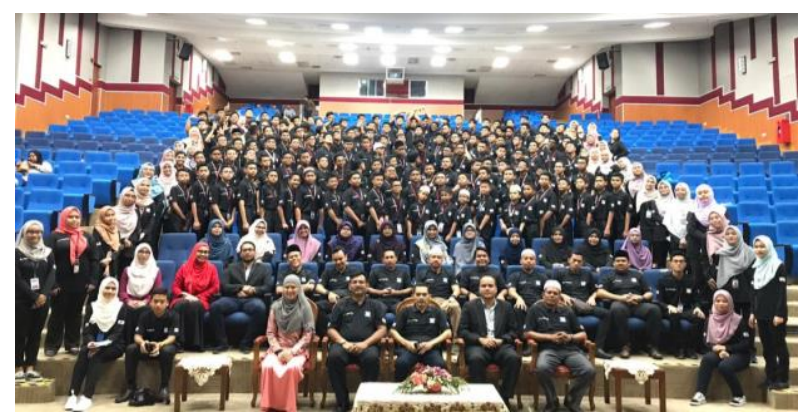

Figure 5 First batch joining this MJIIT CEE program.

\section{CONCLUSION AND WAY FORWARD}

The success of continuous implementation of this program will eventually lead transformation in Malaysia Higher Institution where technology and society develop at the right direction of Industrial Revolution 4.0. The essence of the "knowledge" society is knowledge creation, which will measure greater usefulness of the processed information as opposed to the originally available information by creating new meaning and added value created by creative processing of the available information.

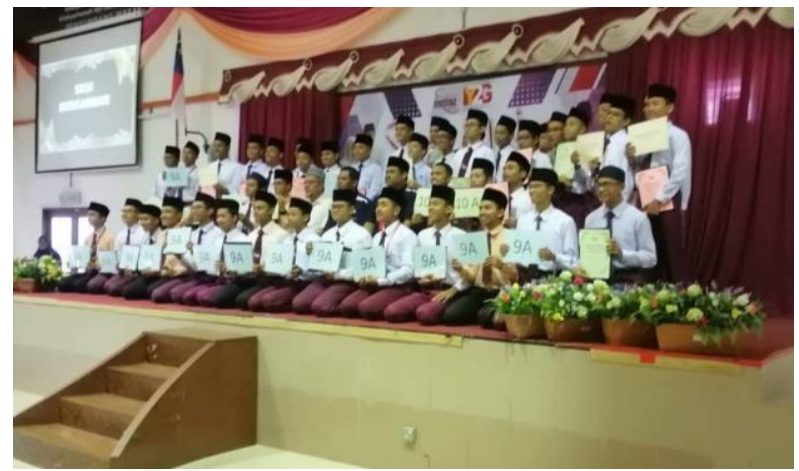

Figure 5 Participants from Imtiaz Melaka had displayed outstanding results in their Sijil Pelajaran Malaysia (SPM) after having great motivation from this program.

This program produces positive outcome through knowledge sharing and motivation for high school students to further their study at university level. Giving them experience of campus life, has also motivated parents and accompanied teacher to encourage each of these students to grab the opportunity to be part of MJIIT in future. Hopefully, this new initiative will in the near future offer greater positive impacts for students, university, and community.

\section{ACKNOWLEDGMENT}

We appreciate involvement of MJIIT management, Kolej Siswa Jaya Principle, Fellows and Student Representatives. Special thanks also to Ministry of Entrepreneur Development (MED) and Muafakat IMTIAZ Melaka for their generous financial support in realising this CEE program.

\section{REFERENCES}

[1] Administration, U. N. D. o. P., and Management, D. (2005). Understanding Knowledge Societies: In twenty questions and answers with the Index of Knowledge Societies: United Nations Publications.

[2] Hooker, M. (2010). Concept Note: Building Leadership capacity for ICT Knowledge Societies in Africa. Global e-schools and Communities Initiative.

[3] Kozma, R. B. (2005). National policies that connect ICT-based education reform to economic and social development. Human Technology: An interdisciplinary journal on humans in ICT environments.

[4] Hasan, H. F. A., Ilias, A., Rahman, R. A., and Razak, M. Z. A. (2008). Service quality and student satisfaction: A case study at private higher education institutions. International Business Research, 1(3), 163175.

[5] Rowley, J. (1997). Beyond service quality dimensions in higher education and towards a service contract. Quality Assurance in Education, 5(1), 7-14.

[6] Soeiro, A. (2006). Continuing engineering education and the third mission of universities. 10th WCCEE. 